\title{
Editorial
}

\section{Headaches in Childhood and Adolescence}

\author{
Florian Heinen $^{1}$ \\ ${ }^{1}$ Department of Paediatric Neurology and Developmental Medicine, \\ Hauner Children's Hospital, Ludwig-Maximilians-University, Munich, \\ Germany
}

Neuropediatrics 2013;44:1-2.

Headaches are one of the most common health complaints worldwide, and the burden of primary headache disorders is well respected in the adult population today. ${ }^{1}$ Hence, major aspects of the conditions have been investigated extensively, and research continues. Based on the gained insights, efforts have been and still are made to ameliorate the health care management and to limit the impact on global public health of headache disorders.

A significant proportion of children and adolescents are affected by relevant headaches as well. ${ }^{2,3}$ However, until recently the issue of pediatric primary headache disorders remains an underrecognized and underinvestigated medical field because research mainly focuses on adults. ${ }^{4,5}$ Therefore, providing adequate health care to pediatric headache patients still constitutes a major challenge for physicians. Concerning almost all aspects of headache conditions, pediatricians need to refer to extrapolated adult data, because appropriate pediatric evidence is scarce. From the clinical point of view, the dilemma starts with deciding on the appropriate diagnostic workup, continues with attributing a diagnosis according to the criteria set by the International Headache Society, includes counseling of patients and parents in aspects of pathogenesis and future course of the condition, and ends with deciding on the best therapeutic strategy for the individual patient. Hence, many patients are underdiagnosed and/or undertreated. In our times, this constitutes a major health care deficit because every child has the right to reliable, adequate, and specific diagnosing, counseling, and treatment of a condition as painful, disabling, and often related to chronification as headache. ${ }^{6,7}$

This issue on Headaches in Childhood and Adolescence covers key aspects of clinical importance in taking care of pediatric headache patients. Three review articles present the most recent updates on the treatment of primary headache disorders in the aspects of pharmacotherapy, biobehavioral, and complementary treatments. ${ }^{8-10}$ The fourth review article focusing on diagnostic considerations provides advice for the

assessment in routine clinical practice. ${ }^{11}$ Two original articles presenting current epidemiologic results on risk factors associated with headaches lend important information for counseling adolescents in the aspect of lifestyle modification. ${ }^{12,13}$ The last article provides advice on the differential diagnosis of migraine-related vertigo. ${ }^{14}$ Taken together, this compilation meets the hallmark of multimodality-today's gold standard in headache management.

From underestimation to evidence-based medicine, children with headache should meet an interested and informed doctor. If this supplement is used for getting updated, focused, and practical information, the guest editor will be more than satisfied.

\section{References}

1 Atlas of Headache Disorders and Resources in the World 2011. A Collaborative Project of World Health Organization and Lifting The Burden. Geneva: World Health Organization; 2011

2 Abu-Arafeh I, Razak S, Sivaraman B, Graham C. Prevalence of headache and migraine in children and adolescents: a systematic review of population-based studies. Dev Med Child Neurol 2010;52(12):1088-1097

3 Blaschek A, Milde-Busch A, Straube A, et al. Self-reported muscle pain in adolescents with migraine and tension-type headache. Cephalalgia 2012;32(3):241-249

4 Hershey AD. Current approaches to the diagnosis and management of paediatric migraine. Lancet Neurol 2010;9(2):190-204

5 Jacobs H, Gladstein J. Pediatric headache: a clinical review. Headache 2012;52(2):333-339

6 Cousins MJ, Lynch ME. The Declaration Montreal: access to pain management is a fundamental human right. Pain 2011;152(12): 2673-2674

7 Brennan F, Carr DB, Cousins M. Pain management: a fundamental human right. Anesth Analg 2007;105(1):205-221

8 Bonfert M, Straube A, Schroeder AS, Reilich P, Ebinger F, Heinen F. Primary headache in children and adolescents: update on pharmacotherapy of migraine and tension-type headache. Neuropediatrics 2013;44(1):3-19

(c) 2013 Georg Thieme Verlag KG Stuttgart · New York
DOI http://dx.doi.org/ $10.1055 / \mathrm{s}-0032-1333436$. ISSN $0174-304 X$.

\author{
Address for \\ correspondence Prof. Florian \\ Heinen, MD, Department of \\ Paediatric Neurology and \\ Developmental Medicine, Hauner \\ Children's Hospital, Lindwurmstr. \\ 4, 80337 München, Germany \\ (e-mail: florian.heinen@med. \\ uni-muenchen.de).
}

Issue Theme Headaches in Childhood and Adolescence; Guest Editor, Florian Heinen, MD. 


\section{Editorial}

9 Kropp P, Meyer B, Landgraf M, Ruscheweyh R, Ebinger F, Straube A. Headache in children: update on biobehavioral treatments. Neuropediatrics 2013;44(1):20-24

10 Schetzek S, Heinen F, Kruse S, et al. Headache in children: update on complementary treatments. Neuropediatrics 2013;44(1):25-33

11 Roser T, Bonfert M, Ebinger F, Blankenburg M, Ertl-Wagner B, Heinen F. Primary versus secondary headache in children: a frequent diagnostic challenge in clinical routine. Neuropediatrics 2013;44(1):34-39

12 Albers L, Milde-Busch A, Bayer O, et al. Prevention of headache in adolescents: population-attributable risk fraction for risk factors amenable to intervention. Neuropediatrics 2013;44(1): 40-45

13 Lehmann S, Milde-Busch A, Straube A, von Kries R, Heinen F. How specific are risk factors for headache in adolescents? Results from a cross-sectional study in Germany. Neuropediatrics 2013;44(1): 46-54

14 Langhagen T, Schroeder AS, Rettinger N, Borggraefe I, Jahn K. Migraine-related vertigo and somatoform vertigo frequently occur in children and are often associated. Neuropediatrics 2013;44(1): $55-58$ 